\title{
Linear nevus sebaceus syndrome
}

INSERM

\section{Source}

INSERM. (1999). Orphanet: an online rare disease and orphan drug data base. Linear nevus sebaceus syndrome. ORPHA:2612

Linear nevus sebaceous syndrome (LNSS) is characterized by the association of a large sebaceous nevus, usually appearing on the face or on the scalp, with a broad spectrum of abnormalities that may affect every organ system, including the central nervous system (brain neoplasms, hemimegalencephaly and lateral ventricle enlargement). 